\title{
Treatment efficacy and safety of chlamydial infection in gynecologic diseases
}

\author{
Jae Eun Chung* \\ Department of Obstetrics and Gynecology, National Health Insurance Service, Ilsan Hospital, Goyang-si, South Korea
}

Received: 16 September 2016

Accepted: 15 October 2016

*Correspondence:

Dr. Jae Eun Chung,

E-mail: jiupark@naver.com

Copyright: $\odot$ the author(s), publisher and licensee Medip Academy. This is an open-access article distributed under the terms of the Creative Commons Attribution Non-Commercial License, which permits unrestricted non-commercial use, distribution, and reproduction in any medium, provided the original work is properly cited.

\begin{abstract}
Background: Chlamydia trachomatis is known to be the causative microorganism of multiple gynecologic diseases such as pelvic inflammatory disease (PID), tubo-ovarian abscess (T-O abscess), and Fitz-Hugh-Curtis syndrome (FHC syndrome). Due to its ability to destruct the celial lining of the fallopian tube and thereby obstructing the passage of the sperm and the egg, chlamydial infection may also result in female infertility. Therefore adequate care of the chlamydial infection is strongly advocated and the currently used treatment of choice is antibiotic coverage such as azithromycin or doxycycline.

Methods: Medical records of the 50 patients who had been admitted to the department of Obstetrics and Gynecology, Ilsan hospital from May 2013 to May 2014, under the diagnosis of pelvic inflammatory disease, tubo-ovarian abscess, and Fitz-Hugh-Curtis syndrome with the confirmatory chlamydia trachomatis PCR positive result were taken into account. Patient's characteristics, complications of the treatment, follow up results were analyzed.

Results: Of the 37 patients given azithromycin $1000 \mathrm{mg}, 7$ vomited completely (18.9\%) requiring doxycycline to cover up. None of the patients taking doxycycline developed vomiting requiring second line of treatment. All of the patients were followed up in the outpatient clinic 4 weeks after being discharged from the hospital. $16.7 \%$ of the azithromycin taking group and $15.0 \%$ of the doxycycline taking group showed positive PCR result which showed no statistical significance.

Conclusions: The advised $1000 \mathrm{mg}$ azithromycin single dosage to cover chlamydial infection is a convenient way of taking the medication, but as gastro-intestinal discomfort may follow, patients with a tendency to develop the complications should be advised to take doxycycline instead. Further research should focus on the test of cure evaluation method to differentiate reinfection from persisting disease.
\end{abstract}

Keywords: Azithromycin, Chlamydia trachomatis, Doxycycline, Pelvic inflammatory disease, Tubal factor female infertility

\section{INTRODUCTION}

Chlamydia trachomatis is one of the most notorious pathogens causing multiple gynecologic diseases such as pelvic inflammatory disease, tubo-ovarian abscess, and Fitz-Hugh-Curtis syndrome. ${ }^{1}$ If chlamydial infection persists without being treated properly, celiac damage in the fallopian tube might pursue and adhesion formation involving the uterus, fallopian tubes, ovaries and the peritoneum might permanently destruct the normal anatomy of the pelvis, resulting in ectopic pregnancy or tubal factor female infertility. ${ }^{2}$

To prevent the dire consequences, adequate treatment eradicating chlamydial infection cannot be overemphasized. Currently $1000 \mathrm{mg}$ of azithromycin taken in a single dosage or $200 \mathrm{mg}$ of doxycycline given for 7 days is the prescription given to cover chlamydial 
infection. $^{3}$ As the regimen of azithromycin is easier to apply and the compliance is high, it is considered as the treatment of choice. In this study, the efficacy and safety of azithromycin coverage concerning chlamydial trachomatis infection in gynecologic diseases are sought.

As the incidence of chlamydial infection is on the rise with the more liberal attitude towards sexual activities in South Korea, precise knowledge of detecting and treating this pathogen cannot be overemphasized.

\section{METHODS}

From May 2013 to May 2014, medical records of the 50 patients who were admitted to the department of Obstetrics and Gynecology in Ilsan hospital due to chlamydial infection were analyzed. Patient characteristics such as age, body mass index (BMI, $\mathrm{kg} / \mathrm{m}^{2}$ ), previous chlamydial infection history, the length of hospital stay, fever, inflammation profiles such as Creactive protein (CRP) and ESR, intrauterine device insertion status were obtained. Patients who needed surgical procedures for the treatment of the diseases were excluded. The intrauterine device was removed prior the administration of the antibiotics.

The presence of Chlamydia trachomatis was confirmed using PCR obtained by vaginal swab. All of the specimens was obtained by a single practitioner (Jae Eun Chung MD) and analyzed in the same institution to minimize the variability that might ensue from the obtaining process.

According the CDC protocol, 1000mg of azithromycin was given as a single dosage. As 1 pill of azithromycin consists of $250 \mathrm{mg}$, a total of 4 pills were given before going to bed. $200 \mathrm{mg}$ of doxycycline was given for 7 consecutive days according the administration schedule.

After properly taking the medication to eradicate chlamydia trachomatis, complications that resulted from taking the medication were analyzed. The more prone complications involving gastro-intestinal system were divided into categories such as nausea, vomiting, and abdominal pain. When vomiting occurred, completely throwing up the medication given, antibiotics regimen was changed to another variety and was given the following day according to the administration schedule.

All of the enrolled patients were followed up in the outpatient clinic. The first follow up was appointed 1 week after the discharge. The second follow up was scheduled 3 weeks after the first outpatient clinic visit. All the patients were checked for the presence of chlamydia trachomatis at the second visit using the same PCR method that had been undertaken while they were admitted in the hospital.

The microbial cure was set as the end point of the efficacy of treatment on the $2^{\text {nd }}$ visit which was 4 weeks after the discharge from the hospital. The safety of taking each medication was calculated for adverse event reported. The two groups were compared using chisquare test and two sample t-test. All analyses were conducted using SAS 9.4 software.

\section{RESULTS}

\section{Characteristics of the patients enrolled}

Of the 50 patients that were treated, 37 initially were given azithromycin and 13 were given doxycycline to eradicate chlamydial infection. Patients were admitted under the diagnosis of pelvic inflammatory disease, tuboovarian abscess, and Fitz-Hugh-Curtis syndrome. Admission was confirmed not solely by the presence of chlamydia trachomatis which was detected by PCR method, but rather according to the signs and symptoms that suggested the need of admission. Those who ended up taking surgical methods of treatment were excluded in the study. No statistical difference found in age, marriage status, Body Mass Index (BMI), previous history of chlamydial infection, intrauterine device insertion status, duration of admission, fever, CRP and ESR elevation (Table 1).

Table 1: Characteristics of the patients.

\begin{tabular}{|llll|}
\hline & $\begin{array}{l}\text { Avithromycin } \\
(\mathrm{n}=37)\end{array}$ & $\begin{array}{l}\text { Doxycycline } \\
(\mathrm{n}=13)\end{array}$ & $\begin{array}{l}\text { P- } \\
\text { value }\end{array}$ \\
\hline Age (years) & $31 \pm 6$ & $30 \pm 7$ & 0.687 \\
\hline Marriage status & $23(62.1 \%)$ & $7(53.8 \%)$ & 0.599 \\
\hline $\begin{array}{l}\text { BMI (body } \\
\text { mass index, } \\
\left.\text { kg/m }{ }^{2}\right)\end{array}$ & $22.3 \pm 3.7$ & $23.1 \pm 2.9$ & 0.149 \\
\hline $\begin{array}{l}\text { Previous } \\
\text { chlamydial } \\
\text { infection }\end{array}$ & $15(40.5 \%)$ & $5(38.5 \%)$ & 0.895 \\
\hline $\begin{array}{l}\text { Intrauterine } \\
\text { device (IUD) }\end{array}$ & $3(8.1 \%)$ & $2(15.4 \%)$ & 0.452 \\
\hline $\begin{array}{l}\text { Duration of } \\
\text { admission } \\
\text { (days) }\end{array}$ & $10 \pm 2$ & $9 \pm 3$ & 0.457 \\
\hline $\begin{array}{l}\text { Fever at the } \\
\text { time of } \\
\text { admission }\end{array}$ & $7(18.9 \%)$ & $3(23.0 \%)$ & 0.747 \\
\hline $\begin{array}{l}\text { C-reactive } \\
\text { protein } \\
\text { elevation }\end{array}$ & $35(94.5 \%)$ & $11(84.6 \%)$ & 0.254 \\
\hline $\begin{array}{l}\text { ESR elevation } \\
\text { C-reactive protein }(\mathrm{CRP})>\end{array}$ & $36(97.3 \%)$ & $12(92.3 \%)$ & 0.50 \\
\hline $\begin{array}{l}\text { ESR> } \\
\text { (1) }\end{array}$ & & \\
\hline
\end{tabular}

\section{Complications after administrating the antibiotics}

Of the 37 patients initially given azithromycin, 7 patients $(18.9 \%)$ threw up completely. As the vomiting occurred, no more effort to re-administer azithromycin was undertaken and instead doxycycline was given the next 
day as scheduled. As the result, a total number of 30 were treated with azithromycin and a total number of 20 were treated with doxycycline. All 7 vomiting patients treated with a single dosage of azithromycin also complained about nausea and abdominal pain. Only 1 patient complained about both nausea and abdominal pain in the doxycycline given group, but no vomiting was noticed. All 7 vomiting patients who was given doxycycline afterwards, endured the 7 days of doxycycline without any specific complaints. One patient with azithromycin developed rash, but it only lasted for 1 day and disappeared with the application of hydrocortisone. In the group taking azithromycin, vomiting, nausea, and abdominal pain occurred more with statistical significance (Table 2).

Table 2: Complications after administrating the antibiotics.

\begin{tabular}{|llll|}
\hline & $\begin{array}{l}\text { Avithromycin } \\
(\mathrm{n}=37)\end{array}$ & $\begin{array}{l}\text { Doxycycline } \\
(\mathrm{n}=13)\end{array}$ & $\begin{array}{l}\mathrm{P} \text { - } \\
\text { value }\end{array}$ \\
\hline Vomiting & $7(18.9 \%)$ & $0(0.0 \%)$ & 0.0378 \\
\hline Nausea & $10(27.0 \%)$ & $1(7.6 \%)$ & 0.0443 \\
\hline $\begin{array}{l}\text { Abdominal } \\
\text { pain }\end{array}$ & $12(32.4 \%)$ & $1(7.6 \%)$ & 0.0185 \\
\hline Rash & $1(2.7 \%)$ & $0(0.0 \%)$ & 0.4528 \\
\hline
\end{tabular}

Follow up results 4 weeks after the discharge from the hospital

Of the 30 patients who successfully took $1000 \mathrm{mg}$ of azithromycin, 5 patients $(16.7 \%)$ showed positive chlamydia PCR result after 4 weeks of the hospital discharge. All 5 of these patients had complained about persisting abdominal pain and vaginal discharge. Four needed readmission because of the discomfort that they could not bear. Two of the re-admitted patients had a new sexual partner after the previous discharge from the hospital. So there was no way of telling whether the chlamydial infection was persistent or re-infected case.

Table 3: Follow up results 4 weeks after the discharge from the hospital.

\begin{tabular}{|llll|}
\hline & $\begin{array}{l}\text { Avithromycin } \\
(\mathrm{n}=30)\end{array}$ & $\begin{array}{l}\text { Doxycycline } \\
(\mathrm{n}=20)\end{array}$ & $\begin{array}{l}\mathrm{P} \text { - } \\
\text { value }\end{array}$ \\
\hline $\begin{array}{l}\text { Chlamydia } \\
\text { PCR }+\end{array}$ & $5(16.7 \%)$ & $3(15.0 \%)$ & 0.8775 \\
\hline $\begin{array}{l}\text { Abdominal } \\
\text { pain }\end{array}$ & $6(20.0 \%)$ & $4(20.0 \%)$ & 0.7200 \\
\hline $\begin{array}{l}\text { Vaginal } \\
\text { discharge }\end{array}$ & $8(26.7 \%)$ & $7(35.0 \%)$ & 0.2737 \\
\hline $\begin{array}{l}\text { Re- } \\
\text { admission }\end{array}$ & $4(13.3 \%)$ & $2(10.0 \%)$ & 0.9242 \\
\hline
\end{tabular}

Out of the 20 patients who ended up taking doxycycline for 7 consecutive days, $3(15.0 \%)$ showed positive PCR results 4 weeks after taking the medication. These patients had complaints about abdominal pain and vaginal discharge, and 2 of them had to be admitted for further conservative care. None of them had new sexual partners sticking to complete abstinence. No statistically significant difference could be noted in the failure of microbial cure rate, occurrence of abdominal pain, occurrence of vaginal discharge, and re-admission rate (Table 3).

\section{DISCUSSION}

Azithromycin $1000 \mathrm{mg}$ given orally as a single dosage is the treatment of choice for the eradication of the chlamydial infection in the field of gynecologic diseases advised by the Centers for Disease Control and Prevention (CDC). ${ }^{3}$ Thirty seven patients took $1000 \mathrm{mg}$ of azithromycin and 7 of them (18.9\%) developed vomiting in this study, completely throwing up the medication given. All of the 7 patients started taking $200 \mathrm{mg}$ of doxycycline for 7 consecutive days following the failure of taking azithromycin. None of the 7 patients developed any further gastro-intestinal discomfort, clearly showing the advantage of taking doxycycline should complications such as vomiting, nausea, and abdominal pain occur.

The safety of taking azithromycin looks much more compromising in this study compared to the other previous reports. ${ }^{4-6}$ All patients were admitted to Ilsan Hospital under various diagnoses such as pelvic inflammatory disease (PID), tubo-ovarian abscess (TO abscess), and Fitz-Hugh-Curtis syndrome (FHC syndrome). As the above mentioned diseases are known to be caused by polymicrobic infection, patients were under the coverage of broad spectrum antibiotics including metronidazole and cephalosporins. ${ }^{7}$ This clinical setting of taking multiple antibiotics at once might have caused more gastro-intestinal irritation resulting in a higher incidence of vomiting thereby having to change the medication to doxycycline. All of the 7 patients who vomited were on NPO (non per os) order because of the possibility of operation under general anesthesia to treat their TO abscess.

Other possible explanation for the higher incidence of vomiting might be found by the distinctive patient's characteristics such as lower BMI value of $19.0 \pm 3.8$, a history of losing weight coercively, taking medications due to dyspepsia, or having concerned about taking antibiotics due to previous experience of vomiting while taking medications. Although taking $1000 \mathrm{mg}$ of azithromycin in a single dosage is a relatively easy and convenient way of administering the medication, if the patient is a strong candidate that might reveal gastrointestinal discomfort after taking 1000mg of azithromycin, it might be wise to prescribe her doxycycline instead. Although a bit more cumbersome, taking 7 consecutive days of doxycycline was a much safer method regarding gastro-intestinal complications. As it is shown in Table 2, only 1 patient had nausea while 
none of the patient developed any other gastro-intestinal complications.

To confirm whether chlamydial infection is eradicated or not, repeat testing of chlamydia trachomatis no sooner than 3 weeks and no later than 3 months is recommended. $^{8}$ All patients were followed up with chlamydia trachomatis PCR (polymerase chain reaction) 4 weeks after the discharge from the hospital. Out of 30 patients, 5 patients $(16.7 \%)$ who took azithromycin had positive chlamydial PCR result. Out of 20 patients, 3 patients $(15.0 \%)$ who took vibramycin had positive chlamydial PCR result. No statistical difference could be found in the two groups. Whether the positive chlamydial PCR test means reinfection or persistence is hard to tell, because the current detection method for chlamydia trachomatis is not specific enough to tell the strain difference. ${ }^{9}$ Resuming sexual activities during the follow up signifies reinfection. All of the re-admitted patients due to deteriorating condition and positive chlamydia result resumed sexual activity after being discharged from the hospital. There is also a possibility of the mere presence of DNA debris of the non-viable chlamydia trachomatis not clearly wiped out from the body. ${ }^{10}$ After taking the antibiotics, the burden of pathogens is suppressed to below the level of detection but the catch up of regrowth might result in persistent infection. Further research in the development of a cost-effective and strain-specific detecting method of the chlamydia trachomatis is strongly warranted, as there are no confirmed testing methods that reliably distinguish between treatment failure and reinfection.

\section{CONCLUSION}

Although the 1000mg azithromycin single dosage is a convenient method of treatment for chlamydial infection with a high compliance, it might result in gastro-intestinal complications such as vomiting necessitating a further administration of doxycycline and causing the patient much discomfort. Therefore before prescribing azithromycin, caution is advised to check on the patient's characteristics that might result in gastro-intestinal complications.

Further research is clearly warranted as the current PCR detecting method of chlamydia trachomatis infection cannot distinguish between reinfection and persistence of the previous infection. Strain-specific detecting method is needed to confirm the efficacy of the previously administered antibiotics, therefore enabling the physician to further guide the patient with scientifically backed up test results.

Funding: No funding sources

Conflict of interest: None declared

Ethical approval: The study was approved by the Institutional Ethics Committee

\section{REFERENCES}

1. Haggerty CL, Gottlieb SL. Risk of sequelae after chlamydia trachomatis genital infection in women. $\mathrm{J}$ Infect Dis. 2010;201(2):S134-55.

2. Low N, Bender N. Effectiveness of chlamydia screening: systematic review. Int $\mathrm{J}$ Epidemiol. 2009;38(2):435-48.

3. Centers for Disease Control and Prevention (CDC). STD Treatment Guidelines. MMWR Recomm Rep. 2010;59:45.

4. Clark KL, Howell MR. Hospitalization rates in female US Army recuits associated with a screening program for Chlamydia trachomatis. Sex Transm Dis. 2002;29(1):1-5.

5. Low N, Egger M, Sterne JA. Incidence of severe reproductive tract complications associated with diagnosed genital chlamydial infection. Sex Transm Infect. 2006;82(3):212-8.

6. Brunham RC, Rekart ML. Considerations on Chlamydia trachomatis disease expression. FEMS Immunol Med Microbiol. 2009;55(2):162-6.

7. Batteiger $\mathrm{BE}, \mathrm{Tu} \mathrm{W}$. Repeated Chlamydia trachomatis genital infections in adolescent women. J Infect Dis. 2010;201:42-51.

8. Geisler WM, Wang C, Morrision SG. The natural history of untreated Chlamydia trachomatis infection in the interval between screening and returning for treatment. Sex Transm Dis. 2008;35(2):119-23.

9. Schachter J, Chernesky MA. Vaginal swabs are the specimens of choice when screening for Chlamydia trachomatis and Neisseria gonorrhoeae: results from a multicenter evaluation of the APTIMA assays for both infections. Sex Transm Dis. 2005;32:725-8.

10. Newman LM, Warner L et al. Predicting subsequent infection in patients attending sexually transmitted disease clinics. Sex Transm Dis. 2006;33:737-42.

Cite this article as: Chung JE. Treatment efficacy and safety of chlamydial infection in gynecologic diseases. Int J Reprod Contracept Obstet Gynecol 2016;5:4160-3. 